\title{
A Crowdsourcing Effort about Mobilizing Students to Forward Thinking of Their Studies
}

\author{
Jan W. OWSIŃSKI ${ }^{1}$, Cristian CIUREA ${ }^{2}$, Florin Gheorghe FILIP ${ }^{3}$ \\ ${ }^{1}$ Polish Academy of Sciences, Warszawa, Poland \\ ${ }^{2}$ Bucharest University of Economic Studies, Bucharest, Romania \\ ${ }^{3}$ Romanian Academy, Bucharest, Romania \\ Jan.Owsinski@ibspan.waw.pl, cristian.ciurea@ie.ase.ro,ffilip@acad.ro
}

The paper presents some preliminary research results, obtained within the framework of the project "Multiparticipant cooperative decision-making: consensus building vs. crowdsourcingbased decisions", concerning the introduction to a crowdsourcing effort meant to mobilize students to forward thinking of their studies. A study was conducted by Bucharest University of Economic Studies and by Warsaw School of Information Technology under the auspices of the Polish Academy of Sciences and relevant data were collected using a questionnaire delivered to Romanian and Polish students. The results were interpreted in order to extract relevant information about expected nature of work after graduating, based on gender, nationality and university. Crowdsourcing solutions are presented in order to reveal their advantages applicable in collaborative environments.

Keywords: Decision-Making, Collaborative, Crowdsourcing, Multi-Participant, Online Education.

DOI: $10.24818 /$ issn14531305/24.4.2020.01

\section{Introduction}

According to [1], the top skills that every student should master in the year 2025 in order to successfully face the challenges of modern jobs provided by the society passing through the fourth technological revolution are as follows:

- Analytical thinking and innovation;

- Active learning and learning strategies;

- Complex problem solving;

- Critical thinking and analysis;

- Creativity, originality and initiative;

- Leadership and social influence;

- Technology use, monitoring and control;

- Technology design and programming;

- Resilience, stress tolerance and flexibility;

- Reasoning, problem-solving and ideation.

The skills mentioned above can be grouped into four broader categories: problem-solving, self-management, working with people, technology use and development.
This paper reports on the preliminary stage of research, oriented at gaining knowledge through a dispersed community, using webbased tools [2]. This preliminary stage involves a questionnaire-based attempt of inquiring the opinions of university students, concerning the ways they are taught, the potential for change, and their own hypothetical participation in such a change, as well as their contribution to it.

The report refers to a questionnaire-based study [3], [4], launched in March 2020 in Romania and Poland and it was accessed by around 70 people. As of the time of that writing, beginning of April 2020, only 47 responses have been obtained to a questionnaire, containing altogether as many as 61 distinct items, organized into, roughly, seven domains. Yet, the responses obtained provide already quite a variety of characteristics, first of all in terms of respondents. Thus, in particular,

- Five university-level schools are represented; 
- Not less than seven directions of study are represented;

- Respondents belong to four nationalities;

- The sample contains both intramural and extramural students;

- The respondents currently are at all the years of study, ranging from 1 to 4;

- The gender balance among respondents is almost perfect;

- The age of respondents ranges from 18 to 37.

Hence, without any discussion of "representativeness", which is here, of course, not really feasible, we can say that the sample acquired is both highly interesting and promising. In what follows, we shall first characterize the questionnaire and give its main purpose and rationale, as well as the organizational framework of the study. Then, we shall give the very first insights from the results, emphasizing both those results that are most directly related to the purpose of the study, and the ones that come out as most interesting and/or surprising.

It should also be noted that - given the timing of the present writing and the coronavirus pandemic - the issues of novel and technology-enabled ways of providing educational services become a highly important, if not outright urgent matter. Due to coronavirus pandemic, it turned out to be necessary to organize online courses, using specialized platforms and videoconferencing systems, such as Moodle, Google Classroom, Google Meet, Microsoft Teams, Zoom, Skype, and so on [5]. Each school and university around the world had to adapt to this radical change and each of them have tried to identify and then apply the best blended-learning platforms.

\section{The Questionnaire and the Study}

The here reported study is being carried out in the framework of the bilateral research project between the Polish and Romanian Academies. The project, entitled "Multiparticipant cooperative decision making: consensus building vs. crowdsourcing-based decisions", is implemented by the Systems Research Institute of the Polish Academy of Sciences and the Bucharest University of Economic Studies.

This project is focused on the multi-person decision processes, with special emphasis on the use of the novel, IT enabled technologies and methodologies [6], [7], [8]. It was deemed appropriate to perform, in the framework of this project, a limited, but valid experimental study, which would potentially constitute an introduction to a broader effort, undertaken in the future.

Hence, a questionnaire-based survey was launched, addressing the university-level students in the schools on the Romanian and Polish sides. The substantive sense of the inquiry is related to the way university education in the respective study directions is carried out, the tools that are and can be used, the potential changes to be introduced and the hypothetical contribution from students. So, the questionnaire contains the following groups of items:

- Basic data on the respondents (the school, the study direction, the intra- or extramural studies, the year of study, nationality, gender, age);

- Expected nature of employment after studies;

- Attitude towards studying (attending lectures and exercises, superfluous lectures, relation to life problems, excess theory in the curriculum, teamwork of students);

- Use of the web (university website, use by lecturers, use by oneself - and for what purposes, use of social media);

- Learning and teaching and the kinds of resources used (with a suggestion of an "appropriate mix" of various kinds of media to be used);

- Necessity of changes in teaching, with indication of particular domains (lectures, lecture materials, exercises, etc.) and the potential tools or instruments;

- Student contribution to the potential change (can students contribute? how? do you have your own idea?).

Let us add that the questionnaire was formulated in English language, while, apparently, at least some of the responding 
students have definite problems with the language, and this could be a source of some - hopefully marginal - errors in responding. The questionnaire was made accessible online, using Google Forms, and is available at: https://forms.gle/kJsWg2aGW5hLqTU99 Figure 1 below shows the statistics regarding gender, nationality and university of students having responded to the questionnaire.

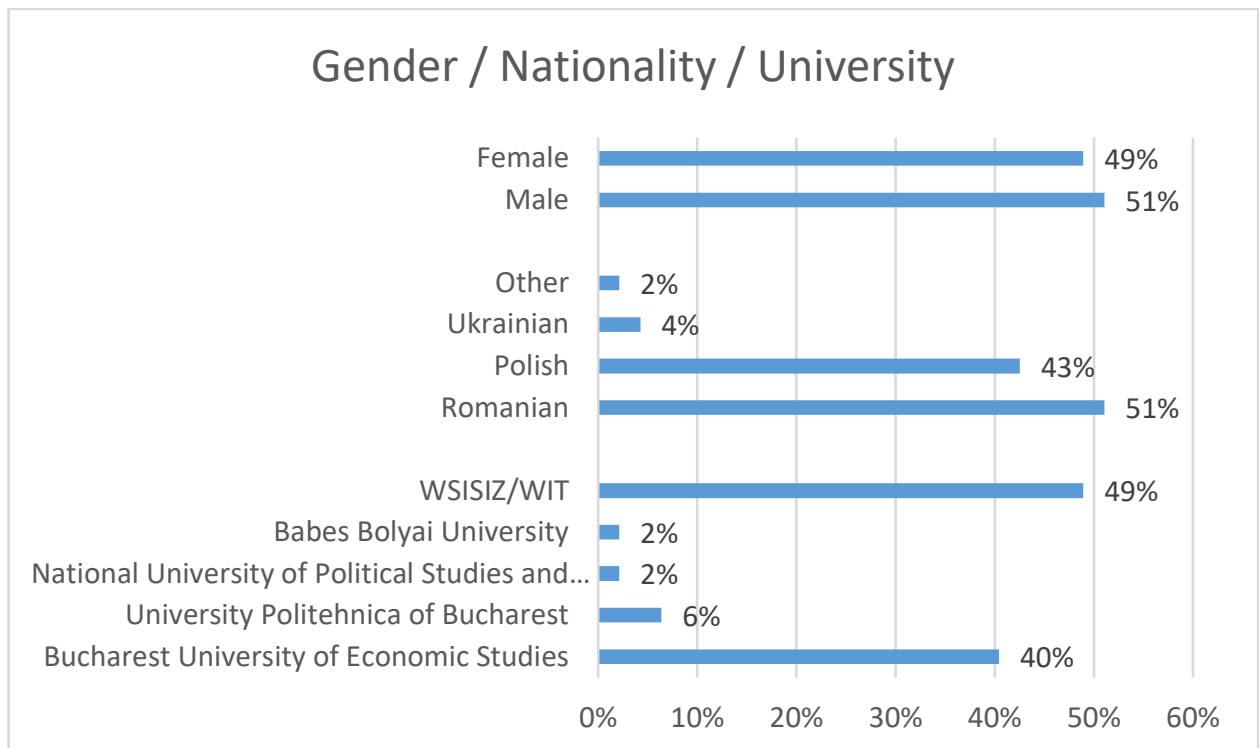

Fig. 1. Statistics concerning gender, nationality and university of the respondents

As seen in Figure 1, the group of respondents is well balanced in terms of gender, as there are 23 females and 24 males. Regarding the nationality, most of respondents are Romanians and Poles, this being explained by the fact that the questionnaire was delivered especially to students from Bucharest University of Economic Studies (ASE) and
Warsaw School of Information Technology (WSISIZ/WIT). This explains also the university affiliation of respondents.

Now, Figure 2 presents the proportion between the students who spend more or less than 10 hours per week for their individual study.

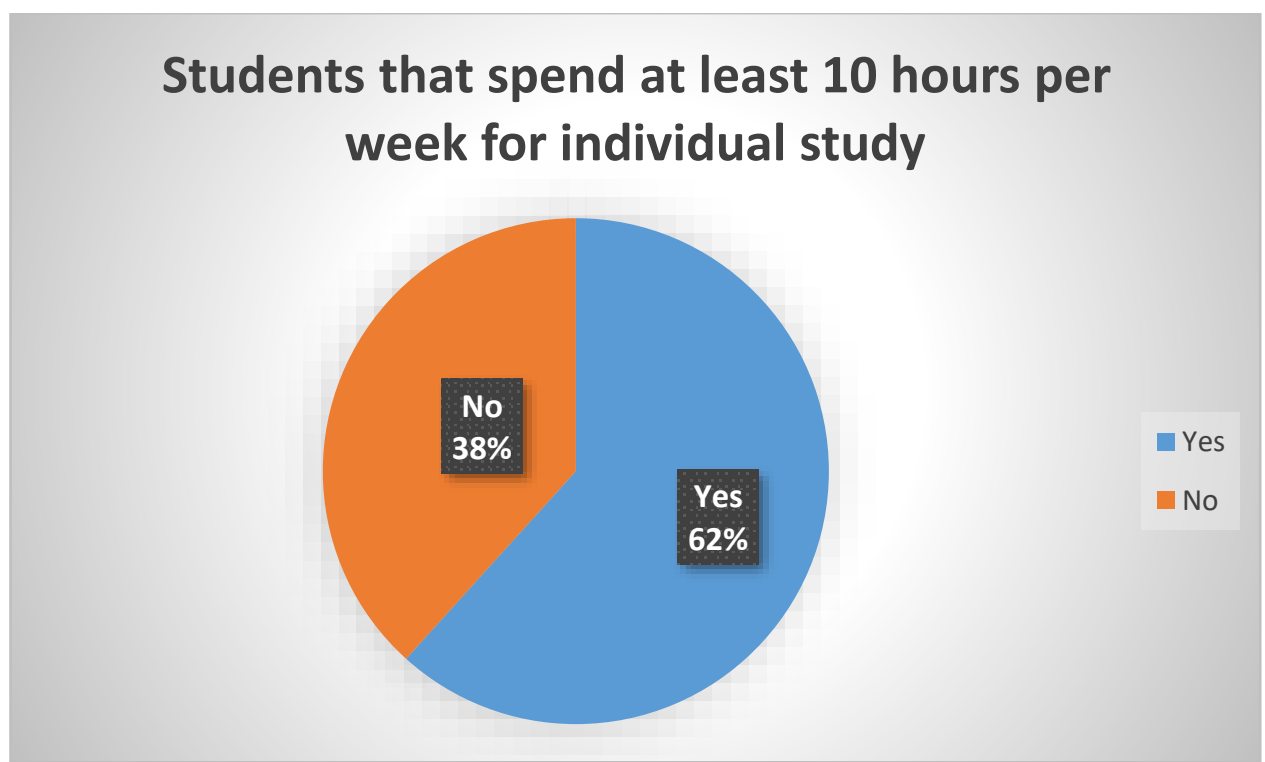

Fig. 2. Statistics regarding the number of hours spent by students for individual study 
As shown in Figure 2, there are 29 students $(62 \%)$ from total of 47 respondents, here considered,, declaring that they spend more than 10 hours per week for individual study. The others, i.e. 18 students $(38 \%)$ declare that they spend less than 10 hours for this purpose. The percentage of students spending less than 10 hours is quite high and we should identify the cause of this situation.
Figure 3 below shows the same statistics, with the responses Yes and No splitted into Romanian and Polish side, in order to see how many students spend more (and less) than 10 hours per week for individual study according to this division. It can be seen from this figure that behaviour of students in this perspective is not very nationality-dependent (especially as the lower part of this figure omits nonPolish students of the school in Warsaw).

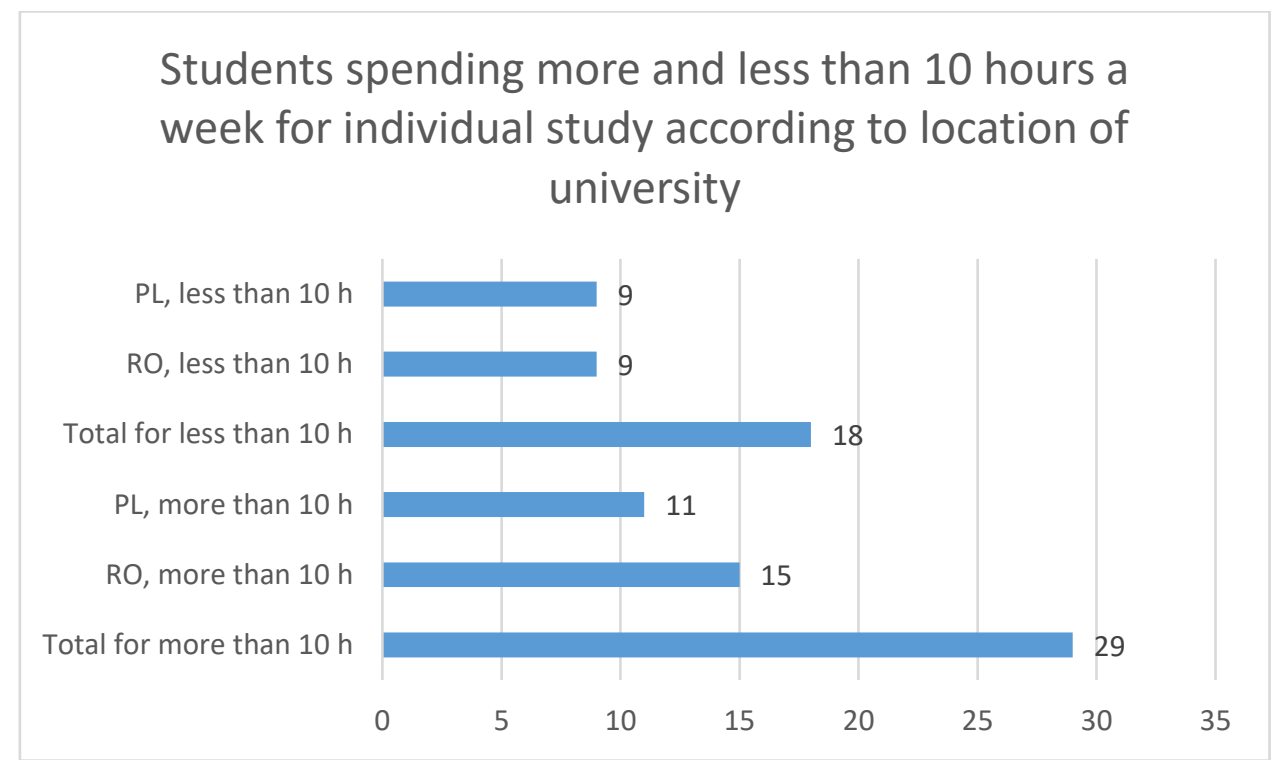

Fig. 3. Statistics regarding the number of hours spent by students for individual study according to the location of the university

Regarding the number of students that declare having an own idea of a tool / method for improving the teaching process and its outcome, Figure 4 shows the respective statistics.

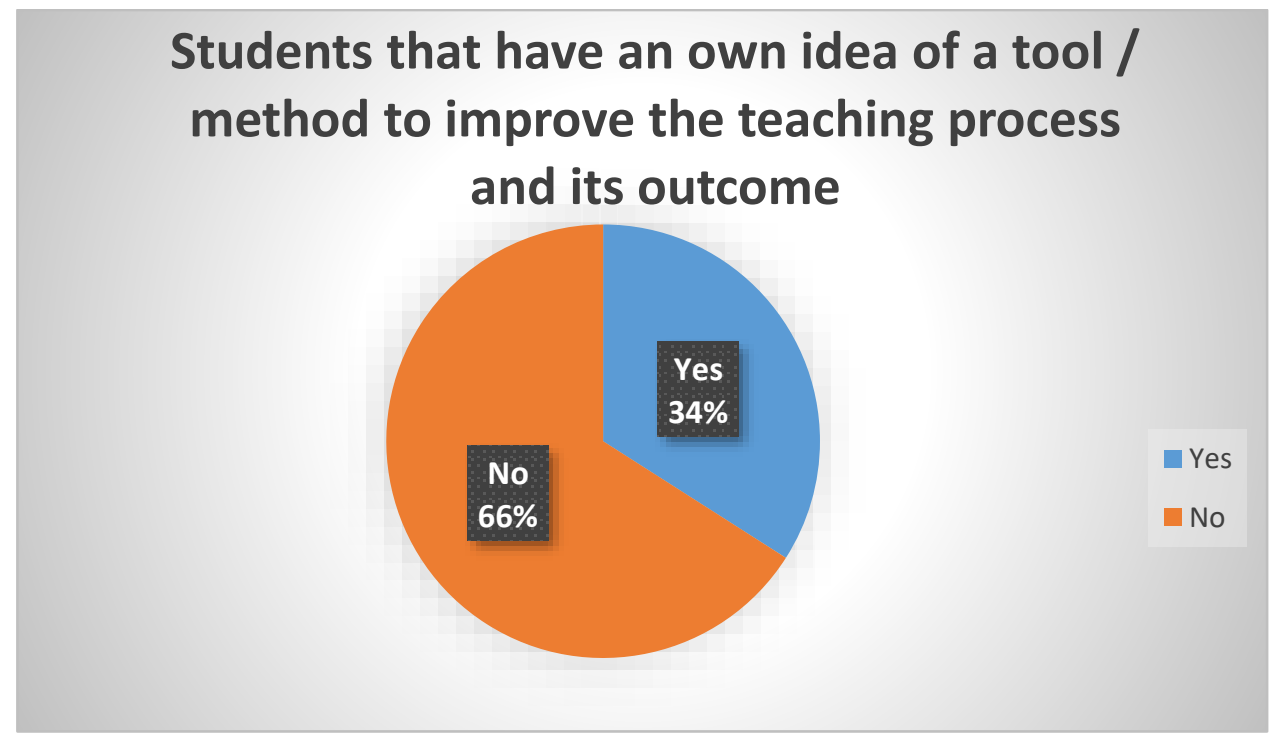

Fig. 4. Statistics regarding the number of students who declare having an own idea of a tool / method for improving the teaching process 
As seen in Figure 4, only 34\% of the respondents declare having an idea concerning a tool or a method to be used in order to improve the teaching process. Concerning the answers of students, some of them recommend audio/video lectures that might be helpful in order to revise a lesson at home, and interactive exercises like, in particular, gamifying tools such as Kahoot [9] and Quizziz [10]. Also, in the opinions of some respondents, teachers should come up with interactive scenarios in order to prepare the students for the real job experience by integrating the theoretical and pragmatic concepts. It must be added, though, that several responses were very enigmatic, like "visual tools" or similar, while, on the other hand, when asked "Can students contribute to the change?" (in teaching methodology) the overwheming response was "Rather yes" (15 responses) and "Definitely yes" (21 responses!), meaning not only a feeling of a need for a change, but the consciousness of the capacity of contributing.

The above can be commented upon in two aspects: 1. It is usual that people who are active (and possibly collaborative at the same time) are a minority, which ought to be mobilised, on purpose, and 2. The gaps between the need for change, the awareness of the potential to contribute, and the actual creativity are, indeed, very broad and deep, which is also a usual phenomenon.

In the above context it is also interesting to look at Figure 5 below, showing the statistics regarding the expectations of students as to the character of their future job after graduation.

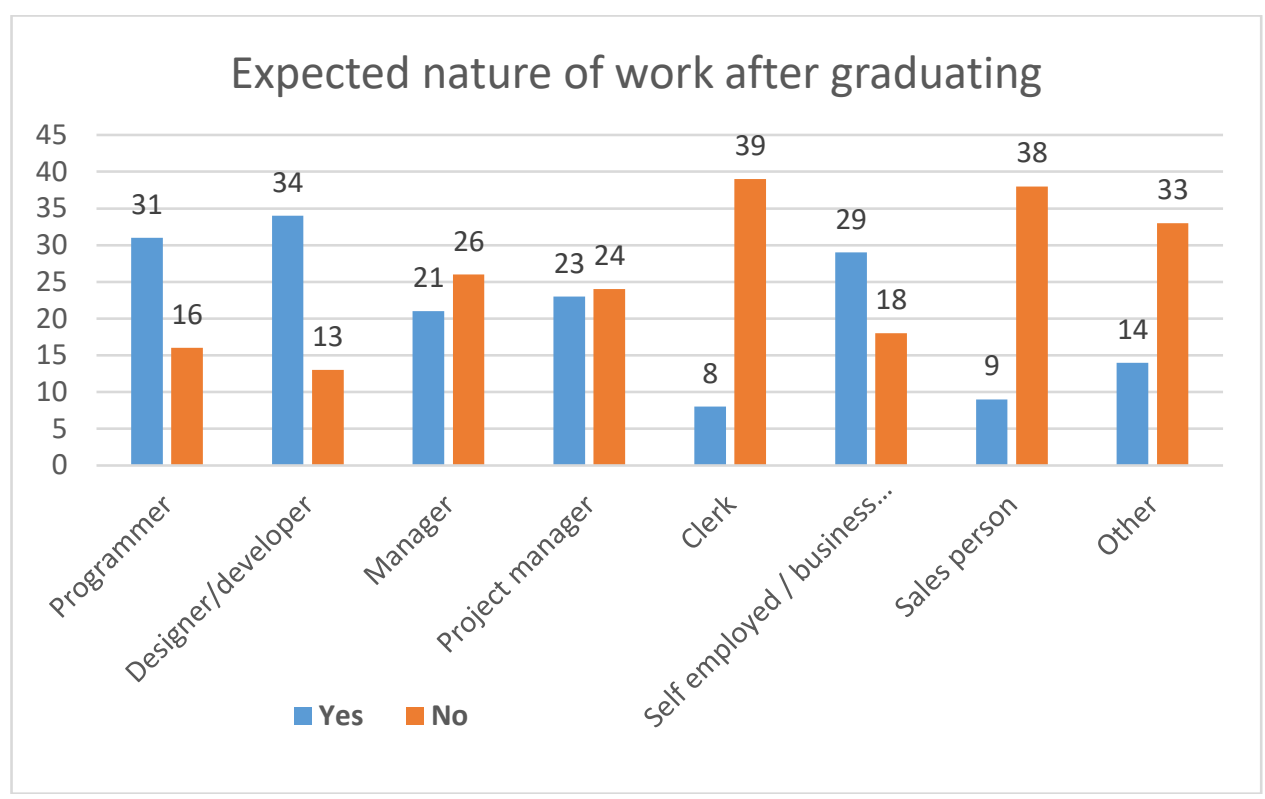

Fig. 5. Statistics related to the expected nature of jobs after graduation

As shown in Figure 5, the most preferred future job designations of students are designer/developer (34 positive answers), programmer (31 positive answers) and self employed/business person (29 positive answers). It is clear, and definitely understandable, that students from our universities do not want to work as sales persons or simple clerks, these two being the most unwanted positions out of the considered set.

\section{Crowdsourcing in Collaborative Environments}

This paper is meant to report from the very initial stage of a study, intended as a probe for a more concrete crowdsourcing effort, this initial stage being devoted to collection and preparation of the data needed for our 
research, in which the participants were Romanian and Polish students and professors. As we know, crowdsourcing can be applied in virtually all activity fields, not only in education, but also in all business and social interactions. It is supposed to contribute to optimization of research, employment, production and marketing processes, by changing the way in which a project is carried out. Crowdsourcing is always a good choice when organizations have to deal with a large number of complex tasks in a relatively short period of time and the significant expertise is insufficient within the organization [11].

In other domains, some crowdsourcingoriented solutions like Waze, Unsplash, Airbnb, and so on are concrete examples of the practice in action. All of the crowdsourced information collected by these platforms allows users to help each other reach their objectives [12]. In a more strictly collaborative environment, when we refer to crowdsourcing, the actual collaboration is achieved electronically almost by definition, usually via the dedicated crowdsourcing platforms, because the members of the crowd are usually located in different places. They collaborate in developing and then choosing a solution, which is agreed upon by the appropriate proportion of them, because the collaborative result is normally better than in the case when they work independently [13]. Crowdsourcing can take place virtually with any type of internet-based collaborative activity, such as co-creation or user innovation [14].

In the case here considered we are at the stage of creating the basis for a potential collaborative effort, while, at the same time, checking the very rationale for such effort (recognition of existence of a need, character of this need, as well as will and capacity of contributing). The work shall continue on both solidifying this basis, including the extension of the sample, and on drawing more in-depth conclusions from the material gathered, particularly in the direction of feasibility of the actual crowdsourcing experiment.

\section{Learning Strategies for Effective Online Learning}

In [15], eight tasks are described that should be undertaken to set the conditions for collaborative expertise, in order that teachers ensure high quality learning strategies to their students:

- Task \#1: shift the narrative to collaborative expertise and student progression;

- Task \#2: agree on what a year's progress looks like across all subjects, schools and system levels;

- Task \#3: expect a year's worth of progress by raising expectations that all students can achieve;

- Task \#4: develop new assessment and evaluation tools to provide feedback to teachers;

- Task \#5: estimate the impact by taking responsibility for the impact of everyone in the school on the progress of students;

- Task \#6: ensure teachers have expertise in diagnosis, interventions and evaluation through teachers working together as evaluators of their impact on their students;

- Task \#7: stop ignoring what we know and scale up success by using the wealth of knowledge that exists in teacher communities;

- Task \#8: link autonomy to a year's progress by studying teachers who are achieving a year of student progress and supporting teachers who aren't.

Considering the pandemic situation of 2020, there was a big change in the way the education was made in the online format. Teachers and students have become dependent of technological solutions for elearning, m-learning and video conferencing, such as Google Classroom, Google Meet, Zoom, Microsoft Teams, Discord, Kahoot, Socrative, Slack, and so many others. It is clear that education cannot be realized just in offline way, without face to face interaction between teacher and students. Even though teachers and students are together in the same video conference meeting, learning is not so effective as in the traditional format, where 
teacher and all students are present in the same physical classroom. Some of students may encounter technical problems in reaching the online courses, or some of them cannot pay attention to online classes because of different environmental factors.

Based on the experience of the authors with online classes using Zoom, Figure 6 below presents the statistics about the students' attendance at a specific online course and seminar carried out on Zoom platform. The average number of minutes for the students' attendance should be 110 minutes, in order to cover even the course or the seminar, but as seen from the graphics for the 86 participants, around a quarter of them participated at both activities and some of them did not attend the full course or the seminar. It is true that more than a half attended at least one of the activities.

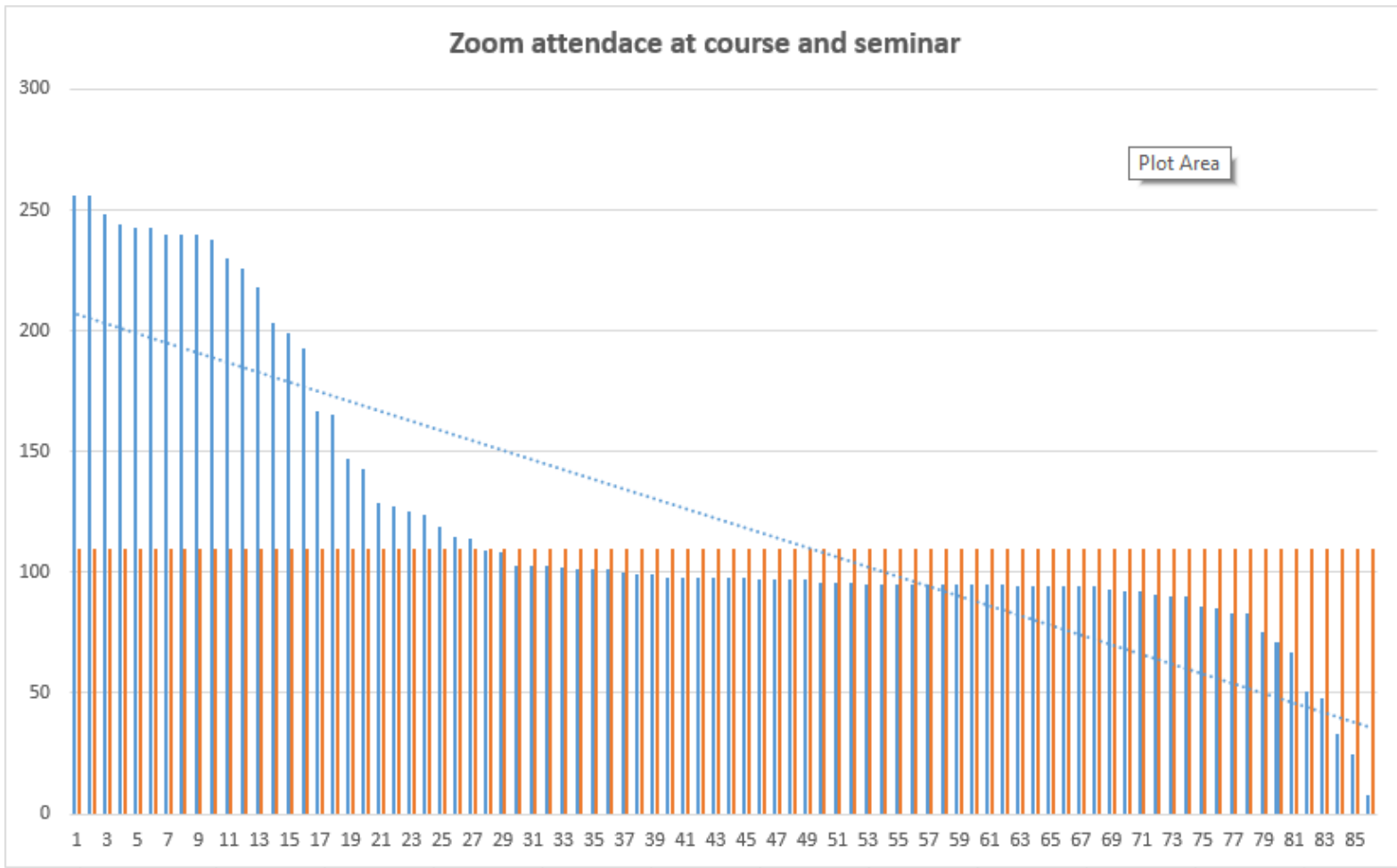

Fig. 6. Illustrative statistics of Zoom attendance at a course and seminar

In the case of students of a master program, at which activities are carried out during weekend, Figure 7 shows the statistics concerning Zoom attendance for 36 participants during a course of around 420 minutes. 


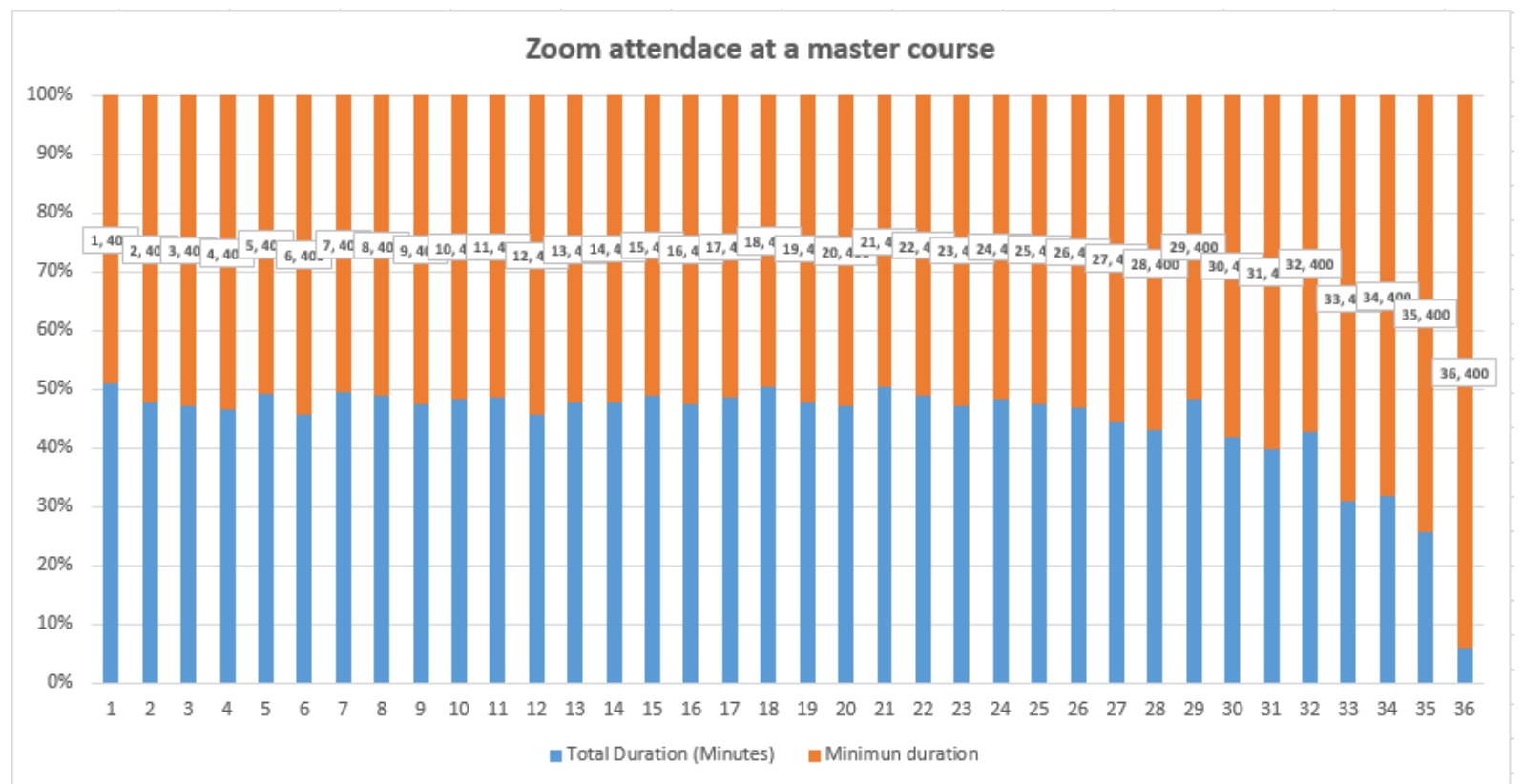

Fig. 7. An instance of statistics on Zoom attendance at a master course

Even though Zoom provides statistics regarding the participants' attendance at definite meetings, teachers cannot know the in detail the situation in terms of how much students were focused on the course presentation and whether they are in front of their screens if the classes are carried out without active camera and microphone. So, teacher interaction with class students is a real challenge in the online learning environment.
The advantages and disadvantages of online learning are described in [16], having as the basis the current experience faced by the educational systems around the world during the pandemic situation. Table 1 below presents these advantages and disadvantages of online learning using technological solutions.

Table 1. Advantages and Disadvantages of Online Learning

\begin{tabular}{|ll|}
\hline Advantages Of Online Learning & Disadvantages of Online Learning \\
\hline Efficiency & Inability to Focus on Screens \\
\hline Accessibility of Time and Place & Technology Issues \\
\hline Affordability & Sense of Isolation \\
\hline Improved Student Attendance & Teacher Training \\
\hline Suits A Variety of Learning Styles & Manage Screen Time \\
\hline
\end{tabular}

In the case of e-learning classes we can highlight the difficulty or even lack of interaction between students and teachers during e-learning classes. It is not enough to upload a PowerPoint presentation for a specific topic if it is not well explained by a teacher, whose role is to to link the students' knowledge with the real-world scenarios. We should underline also the financial aspects of educational achievement because nowadays it is not easy to study abroad and online education can be a solution. But, the technology cannot replace human teachers in the educational system. Modern information and communication technologies just deliver tools to facilitate education.

If we try to summarize the key arguments that one should consider for or against online learning, the arguments for online learning are: distance, costs, available tools and 
devices, anytime and anywhere, pandemic crisis, and the arguments against online learning: lack of interaction, communication problems, knowledge evaluation aspects.

\section{Conclusions}

Irrespective of the field of activity, crowdsourcing represents an innovative way for people to creatively interact, be it in the domain of science, education, culture, or very often - commercial applications, e.g. in the case of a company, needing to activate their audience based on the marketing campaigns which they have prepared and/or launched. Thus, crowdsourcing turns also out to be one of the ways in which consumers might interact with a brand and, helping the marketers to take important decisions about some products [12]. This kind of philosophy of mobilizing customers, audiences, students, users etc. is, of course, applicable in numerous domains.

In our research, crowdsourcing was the most appropriate solution to mobilize students to forward thinking of their studies and professors to adapt their courses to the requests and preferences of students, in order to achieve the best learning level.

In this paper, we tried to juxtapose the results from a sample, oriented at cognition of student capacities and perspectives concerning the change in the way education is performed, with emphasis on online tools, with the actual situation, when online instruments are, in fact, forced upon the schools. It appears that an optimum (effective and efficient) matching of the two requires still quite a considerable effort.

This is definitely very important, as the challenges brought by the pandemic situation and the online learning will certainly influence the way in which the education will take place in the years to come, but as mentioned in [17], the most common issue in conducting online classes is adaptability.

\section{Acknowledgement}

This paper is an extended version of the article presented at the $19^{\text {th }}$ International Conference on Informatics in Economy, IE 2020, 21 May
2020, Bucharest, Romania. This paper was realized in the context of the Joint Research Project "Multiparticipant Cooperative Decision-Making: Consensus Building vs. Crowdsourcing-based Decisions" between Romanian Academy and Polish Academy of Sciences.

\section{References}

[1] World Economic Forum, The Future of Jobs Report 2020, October 2020, Available at: http://www3.weforum.org/docs/WEF Future_of_Jobs_2020.pdf

[2] C. Ciurea, F. G. Filip, "Collaborative Platforms for Crowdsourcing and Consensus-based Decisions in MultiParticipant Environments," Informatica Economică, Vol.23, No.2, 2019, pp. 5-14.

[3] B. Gillham, Developing a Questionnaire: 2nd Edition, A\&C Black, London, 2008.

[4] J. A. Krosnick, "Questionnaire Design", In: D.L. Vannette, J.A. Krosnick (Eds.) The Palgrave Handbook of Survey Research, Palgrave Macmillan, 2018, pp. 439-455.

[5] Team Writer, Top Online Meeting Software to Know, July 31, 2020, Available at:

https://www.techfunnel.com/informationtechnology/11-best-virtual-meetingplatforms-for-business/

[6] C. Ciurea, F. G. Filip, "ComputerSupported Crowdsourcing", Proc. of the $18^{\text {th }}$ Int. Conference on Informatics in Economy, IE 2019, 30-31 May 2019, Bucharest, Romania, pp. 55-60.

[7] F. G. Filip, "DSS - A Class of Evolving Information Systems." In: Dzemyda G., Bernatavičienè J., Kacprzyk J. (Eds.) Data Science: New Issues, Challenges and Applications. Studies in Computational Intelligence, Vol. 869. Springer, 2020, pp. 253-277.

[8] F. G. Filip "A decision-making perspective for designing and building information systems", International Journal Computers Communications \& Control, vol. 7, no. 2 (June), 2012, pp. 264272.

[9] R. Dellos, "Kahoot! A digital game resource for learning," International 
Journal of Instructional Technology and Distance Learning, Vol. 12, No. 4, 2015, pp. 49-52.

[10] J. Batista Bottentuit Junior, “Assessment for Learning with Mobile Apps: Exploring the Potential of Quizizz in the Educational Context," International Journal of Development Research, Vol. 10, No. 01, 2020, pp. 33366-33371.

[11] C. Ciurea, J. W. Owsinski, "Consensus versus Crowdsourcing in Collaborative Decision-Making Applied in Cultural Institutions," Procedia Computer Science, Vol. 162, 2019, pp. 547-554.

[12] R. White, "The Ultimate Guide to Crowdsourcing", HubSpot, 2020, Available at: https://blog.hubspot.com/marketing/crowd sourcing, Accessed on 14 April 2020.

[13] F. G. Filip, C. B. Zamfirescu, C. Ciurea, Computer Supported Collaborative Decision-Making. Springer, 2017.
[14] E. Estellés-Arolas, F. González-Ladrónde-Guevara, "Towards an integrated crowdsourcing definition," Journal of Information Science, Vol. 38, No. 2, 2012, pp. 189-200, https://doi.org/10.1177/016555151243763 $\underline{8}$.

[15] J. Hattie, What Works Best in Education: The Politics of Collaborative Expertise, Pearson, London, 2015, 38 pg.

[16] P. Gautam, Advantages and Disadvantages of Online Learning, October 10, 2020, Available at: https://elearningindustry.com/advantagesand-disadvantages-online-learning

[17] N. Sundar, "No boundaries on educational technology tools for teaching, learning and research," Thiagarajar College of Preceptors Edu Spectra, Vol. 2, No. 2, 2020, pp. 8-14, Available at: http://www.eduspectra.com/V2N2/edu_sp ectra_v2n2_02.pdf

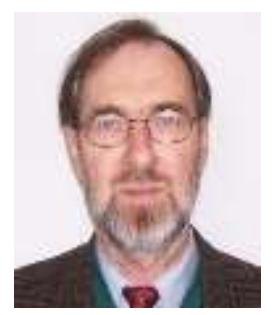

Jan W. OWSIŃSKI, Ph.D., is the Deputy Director for research and research scholar at the Systems Research Institute, Polish Academy of Sciences. He also has following positions: Lecturer at Warsaw School of Information Technology and Management, Executive Editor of the English language quarterly Control and Cybernetics, Editor of Modern Problems in Management, journal of the Faculty of Management, Warsaw School of Information Technology and Management, President at The Interfaces Institute, Secretary General at the Polish Operations and Systems Research Society. He is member of Editorial Boards of several international journals and he published altogether more than 250 papers and more than 30 edited volumes, the latter largely in English.

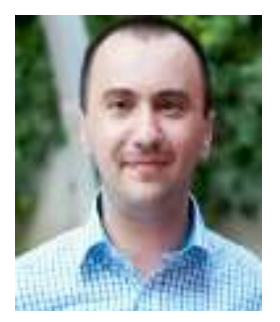

Cristian CIUREA is Associate Professor at the Department of Economic Informatics and Cybernetics at Bucharest University of Economic Studies. He has graduated the Faculty of Economic Cybernetics, Statistics and Informatics at the Bucharest University of Economic Studies in 2007. He has a master in Informatics Project Management (2010) and a PhD in Economic Informatics (2011) at the University of Economic Studies, Bucharest. Cristian has a solid background in computer science and is interested in collaborative systems related issues. Other fields of interest include software metrics, data structures, object oriented programming, windows applications programming, mobile devices programming and testing process automation for software quality assurance. 


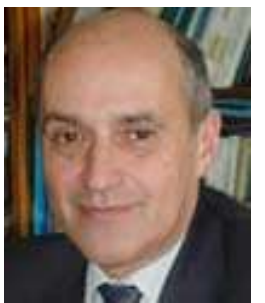

Florin Gheorghe FILIP took his MSc and $\mathrm{PhD}$ in control engineering at the TU "Politehnica" of Bucharest. In 1991 he was elected member of the Romanian Academy (RA). He was a scientific researcher (1970-1990) and managing director (1991-1997) of the National R\&D Institute in Informatics (ICI) in Bucharest and the director of the Library of the Academy (2009-2017). He was elected vice-president of RA in 2000 and re-elected in 2002 and 2006. $\mathrm{He}$ is the chair of "Information Science and Technology" section of the Academy (elected in 2010, reelected in 2015 and 2019). His main scientific interests include large-scale systems, decision support systems, technology management and foresight. 